\title{
Spatially resolved in vivo plant metabolomics by laser ablation-based mass spectrometry imaging (MSI) techniques: LDI-MSI and LAESI
}

\author{
Benjamin Bartels and Aleš Svatoš* \\ Research Group Mass Spectrometry/Proteomics, Max Planck Institute for Chemical Ecology, Jena, Germany
}

OPEN ACCESS

Edited by:

Marc Libault,

University of Oklahoma, USA

Reviewed by:

Sixue Chen,

University of Florida, USA

Zhibo Yang,

University of Oklahoma, USA

*Correspondence: Aleš Svatoš,

Research Group Mass

Spectrometry/Proteomics, Max Planck Institute for Chemical Ecology,

Max-Planck-Gesellschaft,

Hans-Knöll-Straße 8, Jena D-07745,

Germany

svatos@ice.mpg.de

Specialty section:

This article was submitted to

Plant Systems and Synthetic Biology, a section of the journal

Frontiers in Plant Science

Received: 06 May 2015

Accepted: 15 June 2015

Published: 10 July 2015

Citation:

Bartels B and Svatoš A (2015)

Spatially resolved in vivo plant

metabolomics by laser ablation-based

mass spectrometry imaging (MSI)

techniques: LDI-MSI and LAESI.

Front. Plant Sci. 6:471.

doi: 10.3389/fpls.2015.00471
This short review aims to summarize the current developments and applications of mass spectrometry-based methods for in situ profiling and imaging of plants with minimal or no sample pre-treatment or manipulation. Infrared-laser ablation electrospray ionization and UV-laser desorption/ionization methods are reviewed. The underlying mechanisms of the ionization techniques-namely, laser ablation of biological samples and electrospray ionization-as well as variations of the LAESI ion source for specific targets of interest are described.

Keywords: ambient, ionization, mass spectrometry, laser ablation, electrospray

\section{Introduction}

Sample preparation is an important step that precedes acquisition of many kinds of data. However, often sample preparation is associated with artificially altering the biological or biochemical status of the system under study. In order to minimize this effect, we would like to have little to no sample preparation. If we can perform analysis directly in vivo, our data might fully represent the actual system. The usual workflow relies on sample dissection, solvent or thermal extraction and subsequent analysis using chromatographic methods connected to a detector with the needed selectivity. Minimal sample preparation facilitates the analytic process, by allowing people with minimal experience in analytical chemistry to perform the necessary steps without highly involved training. The sheer number of emerging ionization techniques involving minimal, ambient pressure sample preparation demonstrates the current interest, but, sadly, an alphabet soup of abbreviations has been created. Recent reviews (Bhardwaj and Hanley, 2014; El-Baba et al., 2014; Venter et al., 2014) summarize established techniques for most of the possible applications to date, providing an excellent guide for beginners to the field. These techniques are especially interesting for the life sciences (Alberici et al., 2010; Shrivas and Setou, 2012), due to the delicate nature of biological samples. Biological mass spectrometry imaging (MSI) is profoundly profiting from these developments.

In addition to being the least intrusive approach, spatial resolution is an important feature for any imaging technique. Secondary ion mass spectrometry (SIMS) is the ionization technique for mass spectrometry (MS) that offers highest spatial resolution down to reported values of below one micron (Svatos, 2010). Because it uses an ion beam to create secondary ions from the sample (Figure 1A), SIMS is not considered a soft ionization technique. Molecules tend to fragment upon ionization, and the utilization of SIMS is intrinsically linked to extensive sample preparation. SIMS 


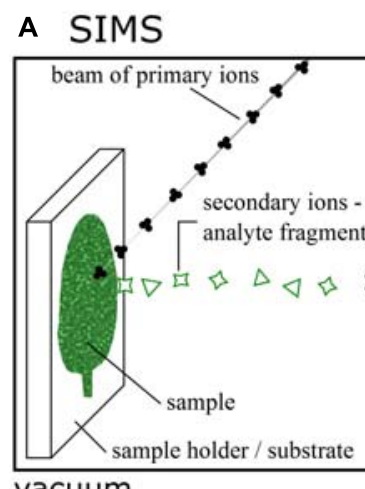

B MALDI
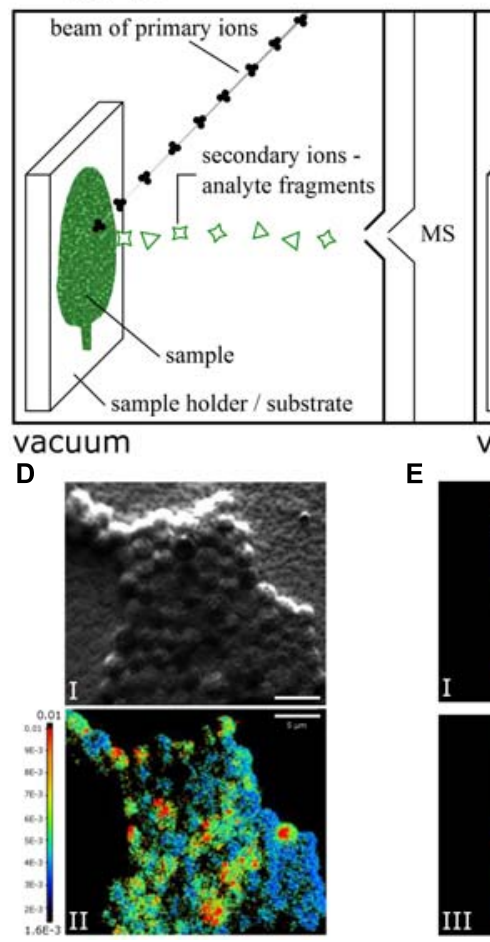

\section{E}

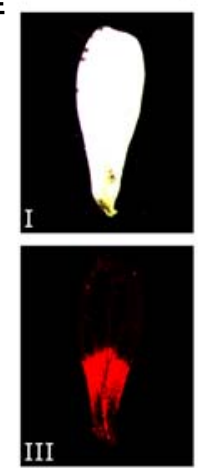

MALDI

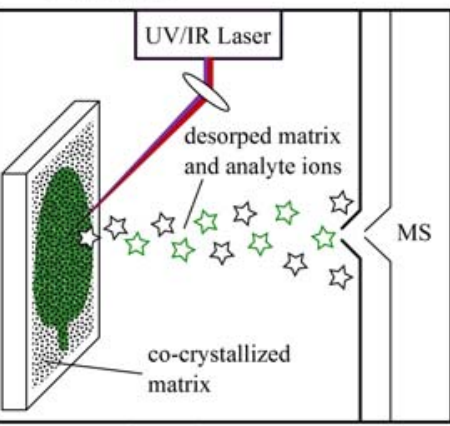

vacuum / ambient pressure c LAESI
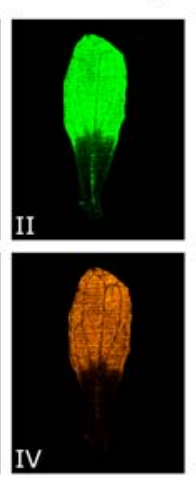

\section{LAESI}

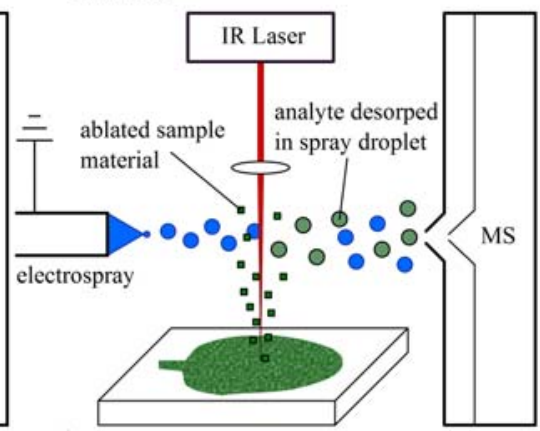

ambient pressure
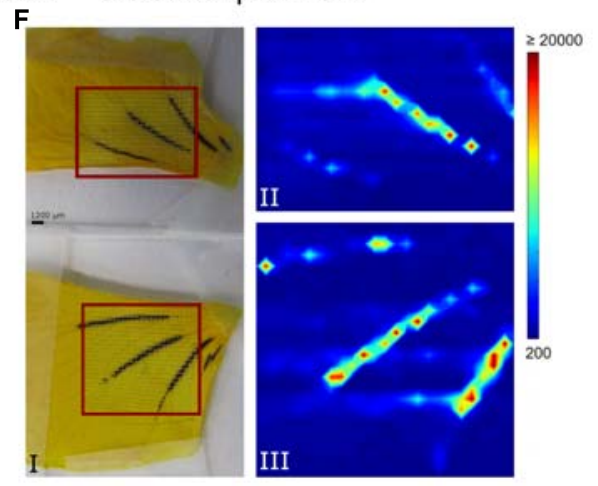

FIGURE 1 | Simplified schematic of (A) secondary ion mass spectrometry (SIMS), (B) matrix-assisted laser desorption/ionization (MALDI), and (C) laser ablation electrospray ionization (LAESI) mass spectrometry imaging (MSI). (D) Color overlay showing the ${ }^{15} \mathrm{~N} /{ }^{14} \mathrm{~N}$ ratio measured with NanoSIMS (I) and the corresponding secondary electron image (II) of Chorizanthe watsonii cells, scale bars $5 \mu \mathrm{m}$. Adapted with permission from (Mohr et al., 2013). (E) Optical image (I) and color overlays of Arabidopsis thaliana petal LDI-MSI in negative ion mode corresponding to kaempferol (II), quercetin (III), and kaempferol rhamnoside (IV) with mass to charge ratios $(\mathrm{m} / \mathrm{z})$ of 285,301 , and 431 , respectively. Adapted with permission from (Hölscher et al., 2009). (F) Viola petals (I) as sampled with conventional LAESI (top) and HA-LAESI (bottom). The color overlays II \& III show the spatial distribution of the selected ion $\mathrm{m} / \mathrm{z} 919.3$ as sampled from the smaller petal with conventional LAESI (II) and from the bigger petal with HA-LAESI (III). Adapted with permission from (Vaikkinen et al., 2013). Copyright 2012 American Chemical Society. has successfully been used on biological samples for imaging (McMahon et al., 1995). In 2013, SIMS was successfully used to investigate the dynamics of nitrogen gas fixation of cyanobacteria at the level of a single cell (Mohr et al., 2013; Figure 1D). MSI of intact biomolecules, however, struggles to reach the level of a bacterial cell. In contrast, recent advances report singlecell resolution on eukaryotes with matrix-assisted ionization techniques, involving extensive sample preparation prior to analysis (Boggio et al., 2011). In early 2015, single-cell imaging was done within a tissue (Li et al., 2015b) utilizing laser ablation electrospray ionization (LAESI), which requires considerably less sample preparation.

A prominent ionization technique used in MSI of large biomolecule imaging is matrix-assisted laser desorption/ionization (MALDI; Caprioli et al., 1997; Bjarnholt et al., 2014; El-Baba et al., 2014). MALDI instrumentation for MSI is commercially available with a spatial resolution of $10 \mu \mathrm{m}$ (FLEX series, Bruker, Bremen, Germany). MALDI requires the samples to be pre-processed extensively by dissolution in and co-crystallization together with a matrix. Originally restricted to vacuum application (Feigl et al., 1983; Karas et al., 1985, 1987), MALDI has since been adapted to work under atmospheric pressure (Laiko et al., 2000; Li et al., 2007). Desorption and ionization of co-crystallized samples with matrix is facilitated by an ultraviolet (UV) laser and recently has also been used in conjunction with infrared (IR) lasers. The matrix molecules absorb most of the energy deposited to the sample by the laser and transfer the energy to the sample analytes more gently than via direct irradiation (Caprioli et al., 1997; Karas and Kruger, 2003), as depicted in Figure 1B. With MALDI, scientists can ionize very big molecules, e.g., proteins, non-destructively, which is one of the reasons why MALDI is used in protein MSI analysis. The method requires reliable matrix deposition and high ion yield (Karas and Kruger, 2003; El-Baba et al., 2014). To image plant cells - some as large as $50 \mu \mathrm{m}$ - the spatial resolution of commercial instruments is sufficient. Laser desorption ionization (LDI) works similarly to MALDI but does not require an externally applied matrix. Because samples are not pre-treated with a matrix, spatial resolution is not compromised by matrix crystals, which could be larger than the studied cells.

Electrospray ionization (ESI) was originally designed to ionize long polymer chains (Dole et al., 1968) and has subsequently evolved (Yamashita and Fenn, 1984; Whitehouse et al., 1985) 
to a commonly used ion source in mass spectroscopy. ESI has become very popular (Bhardwaj and Hanley, 2014), for example, in combination with liquid chromatography (Whitehouse et al., 1985) and been used for MSI as well, especially in the form of desorption electrospray ionization (DESI; Bjarnholt et al., 2014) and the closely related nano-DESI (Lanekoff et al., 2012). These techniques have been shown to achieve 50 and $20 \mu \mathrm{m}$ spatial resolution, respectively (Campbell et al., 2012; Lanekoff et al., 2012). Instead of extracting analytes prior to analysis, both techniques extract analytes in situ prior to ionization directly from the sample surface (Venter et al., 2014). Control over the amount of sample surfaces wetted becomes imperative to avoid cross contamination and maintain spatial resolution.

In 2007, LAESI was introduced (Nemes and Vertes, 2007). The basic principle of LAESI combines LDI and ESI: ablation with a laser, and ionization via ESI, as shown in Figure 1C. However, LAESI uses an IR laser and relies on water present in the sample as a makeshift matrix (Apitz and Vogel, 2005; Nemes et al., 2012), a condition that most samples in life sciences fulfill. This way the deposition of an external matrix is not required, sample handling is simplified and the need to manipulate the samples prior to analysis is reduced. In a LAESI source, IR-laser light of $2940 \mathrm{~nm}$ wavelength is used to irradiate samples. At this wavelength, water has a major peak in its absorption spectrum and thus acts as a chromophore absorbing the deposited energy (Hale and Querry, 1973; Downing and Williams, 1975). Essential work describing the physics of ablating biological tissue with a laser was done recently (Vogel and Venugopalan, 2003b). The event of sample ablation can be split into at least two different phases based on the tensile strength of the sample (Vogel and Venugopalan, 2003a; Apitz and Vogel, 2005). Initially, irradiated sample material is heated and vaporization of molecules from the surface takes place (Vogel and Venugopalan, 2003a). When the energy deposition of the laser is larger than the energy consumption of the vaporization process, the water content of the sample is further heated and driven into a superheated state, leading to phase explosion upon relaxation to a stable state (Vogel and Venugopalan, 2003a; Apitz and Vogel, 2005; Chen et al., 2006). This results in material expulsion as well as tissue rupture and is primarily responsible for ablation efficiency
(Apitz and Vogel, 2005). The resulting ablation plume consists mostly of neutral matter in the form of nanoparticles, droplets, and large particulates. Experimental data suggest droplets from the electrospray plume intercept and fuse with the ablation plume nanoparticles, extracting analytes in the process (Nemes and Vertes, 2007). At this point, post-ionization by ESI takes over. A review of the research done on most of the aspects governing ESI (Kebarle and Verkerk, 2009) provides an excellent introduction to the field. Once ions have been generated from the sample, mass analyzers provide the means of detection.

The following section provides examples of instrumentation to illustrate the capabilities of the LAESI technique. LAESI displays promising potential for application in animal and plant metabolomics (Stolee et al., 2012; Stopka et al., 2014) and MSI of living plant tissue (Nemes and Vertes, 2007; Li et al., 2015b). For more information on different types of MSI methods, refer to Table 1.

\section{Application of LAESI}

The first realization of a LAESI ion source, as described by Nemes and Vertes (2007), consisted of a custom-built electrospray system, an Er:YAG laser tuned to a wavelength of $2940 \mu \mathrm{m}$, and a time-of-flight (TOF) mass spectrometer. One of the proofof-concept experiments carried out was metabolic profiling of Tagetes patula seedlings in vivo. Several tentative assignments of metabolites from roots, leaves and stems were made. For that, accurate mass measurements, isotope patterns and metabolomic databases of model organisms such as Arabidopsis thaliana were considered. Cautious use of these databases was justified under the presumption that plants share certain metabolomics features (Nemes and Vertes, 2007; Nemes et al., 2008). Although LAESI is classified as a destructive method, seedlings subjected to the single-shot laser ablation were reported to survive the $350 \mu \mathrm{m}$ wide ablation craters in roots, leaves, and stems.

Nemes et al. (2008) used a combination of LAESI and TOF mass analyzer techniques to show the usability of LAESI for MSI of plant tissues. Leaves of Aphelandra squarrosa with variegation patterns were subjected to two-dimensional imaging with a

TABLE 1 | lonization techniques used for mass spectrometry imaging (MSI) of biological samples.

\begin{tabular}{|c|c|c|c|}
\hline Ionization technique & Typical spot size/spatial resolution & Requirements/sample preparation & Reference \\
\hline $\begin{array}{l}\text { Secondary ion mass spectrometry } \\
\text { (SIMS) }\end{array}$ & $\begin{array}{l}\sim 100 \mathrm{~nm} \text {, subcellular resolution } \\
\text { possible }\end{array}$ & $\begin{array}{l}\text { Sample must be stable enough in } \\
\text { vacuum environment }\end{array}$ & $\begin{array}{l}\text { McMahon et al. (1995), Colliver } \\
\text { et al. (1997), Mohr et al. (2013) }\end{array}$ \\
\hline $\begin{array}{l}\text { Matrix-assisted laser } \\
\text { desorption/ionization (MALDI) }\end{array}$ & $\begin{array}{l}\sim 10 \mu \mathrm{m} \text { with commercially available } \\
\text { instruments }\end{array}$ & $\begin{array}{l}\text { Matrix molecules need to be } \\
\text { co-crystalized with sample }\end{array}$ & $\begin{array}{l}\text { Karas and Kruger (2003), El-Baba } \\
\text { et al. (2014) }\end{array}$ \\
\hline Laser desorption/ionization (LDI) & $\begin{array}{l}\sim 5 \mu \mathrm{m} \text { with commercially available } \\
\text { instruments }\end{array}$ & $\begin{array}{l}\text { UV-absorbing analytes increase } \\
\text { desorption/ionization }\end{array}$ & $\begin{array}{l}\text { Hölscher et al. (2009), Kroiss et al. } \\
\text { (2010), Hoelscher et al. (2014) }\end{array}$ \\
\hline $\begin{array}{l}\text { Matrix-assisted laser desorption } \\
\text { electrospray ionization (MALDESI) }\end{array}$ & $\begin{array}{l}\text { Spot size is } 250-300 \mu \mathrm{m} \text {, spatial } \\
\text { resolution of } 45 \mu \mathrm{m} \text { with oversampling } \\
\text { reported }\end{array}$ & $\begin{array}{l}\text { Similar to MALDI but higher ion yield } \\
\text { achievable through post ionization step }\end{array}$ & $\begin{array}{l}\text { Sampson et al. (2006), Robichaud } \\
\text { et al. (2014) }\end{array}$ \\
\hline $\begin{array}{l}\text { Desorption electrospray ionization } \\
\text { (DESI) }\end{array}$ & $\begin{array}{l}\text { 50-20 } \mu \mathrm{m} \text { spatial resolution, depending } \\
\text { on source instrumentation }\end{array}$ & $\begin{array}{l}\text { No particular sample preparation needed } \\
\text { but sensitive to surface wetting }\end{array}$ & $\begin{array}{l}\text { Campbell et al. (2012), Lanekoff } \\
\text { et al. (2012) }\end{array}$ \\
\hline $\begin{array}{l}\text { Laser ablation electrospray ionization } \\
\text { (LAESI) }\end{array}$ & $\begin{array}{l}350-15 \mu \mathrm{m} \text { spot size, depending on } \\
\text { source instrumentation }\end{array}$ & $\begin{array}{l}\text { Water in sample, e.g., in the form of } \\
\text { cytosol }\end{array}$ & $\begin{array}{l}\text { Nemes and Vertes (2007), Shrestha } \\
\text { and Vertes (2009) }\end{array}$ \\
\hline
\end{tabular}


spatial resolution of $400 \mu \mathrm{m}$ and depth profiling with a resolution of $50 \mu \mathrm{m}$. The actual spot size of the laser was reported as $350 \mu \mathrm{m}$, but a bigger step size was chosen to limit cross-talk in the acquisition of mass spectra. Nemes et al. (2008) were able to show that localization of the secondary metabolites kaempferol and luteolin, as well as certain derivatives with sugar moieties, coincides with the variegation pattern. The spatial distribution was then combined with the information gathered from depth profiling to visualize the spatial distribution of secondary plant metabolites in three dimensions. Depth profiling was realized by consecutive irradiation of the same spot (Nemes et al., 2008, 2009).

The work of Nemes et al. $(2008,2009)$ showed the feasibility of a LAESI ion source for analyzing and imaging metabolites in plant samples. Shrestha and Vertes (2009) improved upon the LAESI concept by using an etched, $\mathrm{GeO}_{2}$-based glass fiber to focus and deliver the laser to the sample. This made it possible to decrease the diameter of the ablation marks to slightly larger than $2 \mathrm{R}$, with $\mathrm{R}$ being the radius of the glass fiber tip's curvature, reported as roughly $15 \mu \mathrm{m}$ in size and as forming ablation craters of ca. $30 \mu \mathrm{m}$. The metabolome of single epithelial cells from Allium cepa and Narcissus pseudonarcissus bulbs was analyzed and compared across species, but also compared to relative species within a particular sample tissue. Interestingly, the same cell type, $A$. cepa bulb epithelial cells and their $N$. pseudonarcissus equivalent, showed different contents of metabolites, with oligosaccharides and alkaloid, respectively, abundant (Shrestha and Vertes, 2009). By looking at epithelia from different layers of the same bulb, differently aged $A$. cepa cells were compared. The content of arginine was reported to decrease with increasing cell age, while the alliin gradient was oriented the other way around. Cells in an A. cepa bulb are older when located in the outer layers. Shrestha et al. (2011) also determined the influence of ablating event on single cells within a tissue on the surrounding cells and found no major disturbance compared to similar cells in undisturbed areas of the sampled tissue.

The same experimental set-up was also used to find biomarkers in the oil glands of Citrus aurantium leaves. For the initial mass spectra from achlorophyllous cells of C. auratium, leaf oil glands and epidermal cells from distant parts of the same leaf were first measured and then compared. Different terpenes and terpenoids were found in the oil gland cells, which are absent in the epidermal cells and which contained flavonoids compounds not present in the gland cells (Shrestha et al., 2011).

The step to subcellular resolution was taken by Stolee et al. (2012). The LAESI set-up described previously (Shrestha and Vertes, 2009) was improved upon by adding a micro-dissection needle made out of tungsten. Prior to sample irradiation by the IR laser, the needle with a tip diameter of approximately $1 \mu \mathrm{m}$ was used to cut open and peel back the cell wall of $A$. cepa epithelial cells. Metabolites such as hexose and alliin were reportedly found with higher abundance in cytosolic areas of a cell, whereas the amino acids arginine and glutamine were found more commonly in the area of the cell nucleus (Stolee et al., 2012). However, the improvement made by ablating the sample precisely goes hand in hand with the small sample volume from which ions can be generated. This limitation obviously reduces sensitivity of the method and poses a general problem of spatially confined ionization techniques.

Depending on the properties of the electrospray solution used, imaging substances with strongly diverging polarities may be difficult to ionize simultaneously. A LAESI source was modified to address this problem (Vaikkinen et al., 2013). By adding a nebulizer chip blowing heated nitrogen gas toward the MS orifice, a more efficient ionization of both polar and nonpolar compounds was expected (Careri et al., 1999; Boscaro et al., 2002). Compared to an unmodified LAESI ion source, heat-assisted LAESI (HA-LAESI) has shown to better ionize compounds with low polarity, as demonstrated on Persea americana mesocarp (Vaikkinen et al., 2013). A high abundance of signals assigned to triglycerides was observed in the MS spectrum measured with HA-LAESI. These particular peaks were less pronounced when using LAESI. To demonstrate imaging capabilities, Vaikkinen et al. (2013) used Viola flower petals and visualized the distribution of glycosides known to be present in Viola (Saito et al., 1983) as shown in Figure 1F. To further improve on ionizing low and non-polar compounds, a krypton discharge lamp for photo-ionization was added to the LAESI set-up to ionize anisole molecules with UV light that in turn ionize analytes in subsequent reactions taking place in the gas phase. The electrospray was exchanged for a nebulizer chip with an anisole and heated nitrogen gas flow (Vaikkinen et al., 2014), very similar to HA-LAESI. The technique was called laser ablation atmospheric pressure photoionization (LAAPPI). MSI was performed on Salvia officinalis leaves, and tentative assignment of multiple terpene and terpenoid compounds could be made (Vaikkinen et al., 2014). Because the IR light was focused using a lens instead of an etched glass fiber (Shrestha and Vertes, 2009) as described by Nemes et al. (2008), spatial resolution was reported as $400 \mu \mathrm{m}$.

Until recently, MSI was performed by measuring a sample step-wise using a predefined raster. Resolution of the mapping thus depended on the smallest possible step preventing pixel cross-talk. Li et al. (2015b) reported a procedure for LAESIMSI, integrating light microscopy to assess and identify single cells within a sample tissue. An imaging raster consisting of cells defining that particular sample tissue was then created and used for systematic cell-by-cell imaging. Feasibility and proofof-concept experiments on A. cepa bulb and Lilium longiflorum were performed using the precision of LAESI with an etched, $\mathrm{GeO}_{2}$-based glass fiber (Shrestha and Vertes, 2009). The capacity for separating isobaric and structurally isomeric ions in LAESIMSI experiments was demonstrated by Li et al. (2015a) on Pelargonium peltatum leaves and mouse brain tissue.

Trying to make LAESI more compatible with complementary methods such as light microscopy, Compton et al. (2015) tried to spatially separate laser ablation from ESI. After ablation, the produced plume was carried into transfer tubing with nitrogen gas, and analytes were ionized with ESI after emerging from the $60 \mathrm{~cm}$ long tubing. Parts of Viola and Acer sp. were analyzed using remote-LAESI as proof-of-principle experiments. Signal strength was reported to be $27 \%$ of the intensity detected using conventional LAESI (Compton et al., 2015). 
Laser ablation electrospray ionization was recently used as one of the methods to confirm the quantitative MSI of surfaceoccurring glucosinolate on A. thaliana leaf surfaces (Shroff et al., 2015). Data obtained from LAESI and liquid extraction surface analysis (LESA; Kertesz and Van Berkel, 2010) unambiguously supported the data obtained using a 9-aminacridine matrix sublimed on the leaves and imaged using vacuum MALDI-MSI.

In addition, LAESI has been applied to human- and animalderived samples. The applicability of LAESI to blood and serum samples for medical purposes as well as antihistamine quantification directly from human urine samples has been shown (Nemes and Vertes, 2007). Since then, metabolomic and lipidomic analysis of the electric organ of Torpedo californica (Sripadi et al., 2009), rat and mouse brain (Nemes et al., 2010; Shrestha et al., 2010), fish gills (Shrestha et al., 2013), and other samples (Parsiegla et al., 2012; Shrestha et al., 2014) has been reported. A LAESI system, DP-1000 LAESI, is now available commercially from Protea Bioscience (Morgantown, WV, USA). The spatial resolution of the system is ca. $200 \mu \mathrm{m}$ and can be attached to diverse mass spectrometers. Early data on MSI of pesticides, mycotoxines, and plant metabolites from lemon or rose leaves have recently been published (Nielen and van Beek, 2014) using this source.

\section{Application of LDI-MSI in Planta}

Laser desorption ionization can be applied in planta, as many important secondary metabolites contain conjugated doublebond systems like aromatic/heteroaromatic rings and show strong UV adsorption at 337 or $355 \mathrm{~nm}$; both levels are emitted by the most common UV lasers. Plant pigments and compounds of the polyketide family readily absorb UV light and serve to desorb/ionize themselves. Elimination of MALDI matrices makes MSI in cellular resolution possible; see, for example, hypercins in glandular pigment cells of Hypericum perforatum or quercetin glucosides in A. thaliana petals or sepals as demonstrated by Hölscher et al. (2009) and shown in Figure 1E. A vacuum MALDI system Ultraflex (Bruker) with smart beam technology provided $10 \mu \mathrm{m}$ spatial resolutions. Hypercins were shown to co-localize with dark pigment glands. A recent advance in developing systems with even higher spatial resolution as well as mass accuracy was commercialized in the AP-SMALDI imagine10 (TransMIT, Giessen, Germany) source attached to a Q-Exactive system with orbital mass analyzer (Thermo Scientific, San Jose, CA, USA). Laser spot sizes smaller than $5 \mu \mathrm{m}$ are possible, and LDI measurements can be performed at ambient conditions thus preventing plant sample desiccation and deformation. This

\section{References}

Alberici, R. M., Simas, R. C., Sanvido, G. B., Romao, W., Lalli, P. M., Benassi, M., et al. (2010). Ambient mass spectrometry: bringing MS into the "real world". Anal. Bioanal. Chem. 398, 265-294. doi: 10.1007/s00216-010-3808-3

Apitz, I., and Vogel, A. (2005). Material ejection in nanosecond Er : YAG laser ablation of water, liver, and skin. Appl. Phys. A Mater. Sci. Process. 81, 329-338. doi: 10.1007/s00339-005-3213-5 method is not limited to plants as was documented by MSIs of nematodes ingesting plant toxins from infected banana roots (Hoelscher et al., 2014) or on various MSI of antibiotics produced by actinomycetes on beewolf cocoons (Kroiss et al., 2010). LDI coupled with a plasma torch, also known as laser ablation inductively coupled plasma MS (LA-ICP-MS), is used for imaging distribution of metals in planta (Becker et al., 2010) or to localize proteins labeled with antibodies containing a metal-reporter ion (Bendall et al., 2011). This method shows extreme sensitivity, and as desorbed tissue debris undergoes post-ionization in a plasma torch, the technique is also quantitative.

\section{Conclusion}

Although plant tissues have been employed to characterize LAESI since the introduction of the technique in 2007, its application in plant metabolomics and MSI is still limited to proof-of-concept experiments, for example, with onion ( $A$. cepa) bulbs. This limited use may be a result of the apparent dominance of MALDI applications in imaging with high spatial resolution and the initial barrier of acquiring a LAESI source, since instrumentation with high spatial resolution is not yet commercially available. Even custom-built realizations do not reach the benchmark resolutions reported for MALDI. Advantages such as the absence of an external matrix and the potential for direct correlation with microscopically gathered data through the means of software evaluation may, however, promote the use of LAESI over time. Interdisciplinary work, in particular, which is usually characterized by a wide variety of methods and thus depends on data correlation, might profit from these ionization techniques. As the literature reviewed here shows, the performance of the LAESI ion source is sufficient for utilization in larger studies of plant metabolomes, especially in MSI of target metabolites, and for answering current biological questions. The same can be said about LDI. It is less intrusive than MALDI, because it does not require an externally applied matrix. Additionally, the spatial resolution is not compromised by the matrix crystals, which could be larger than the studied cells. Typically, using diverse orthogonal methods can be fruitful and is of help in reducing experimental bias.

\section{Acknowledgments}

We thank Emily Wheeler for editorial assistance and the Max Planck Society for a stipend to BB and for financial support.

Becker, J. S., Zoriy, M., Matusch, A., Wu, B., Salber, D., and Palm, C. (2010). Bioimaging of metals by laser ablation inductively coupled plasma mass spectrometry (LA-ICP-MS). Mass Spectrom. Rev. 29, $156-175$.

Bendall, S. C., Simonds, E. F., Qiu, P., Amir, E. A. D., Krutzik, P. O., Finck, R., et al. (2011). Single-cell mass cytometry of differential immune and drug responses across a human hematopoietic continuum. Science 332, 687-696. doi: $10.1126 /$ science. 1198704 
Bhardwaj, C., and Hanley, L. (2014). Ion sources for mass spectrometric identification and imaging of molecular species. Nat. Prod. Rep. 31, 756-767. doi: 10.1039/c3np70094a

Bjarnholt, N., Li, B., D’Alvise, J., and Janfelt, C. (2014). Mass spectrometry imaging of plant metabolites - principles and possibilities. Nat. Prod. Rep. 31, 818-837. doi: 10.1039/C3NP70100J

Boggio, K. J., Obasuyi, E., Sugino, K., Nelson, S. B., Agar, N. Y., and Agar, J. N. (2011). Recent advances in single-cell MALDI mass spectrometry imaging and potential clinical impact. Expert Rev. Proteomics 8, 591-604. doi: 10.1586/epr.11.53

Boscaro, F., Pieraccini, G., La Marca, G., Bartolucci, G., Luceri, C., Luceri, F., et al. (2002). Rapid quantitation of globotriaosylceramide in human plasma and urine: a potential application for monitoring enzyme replacement therapy in Anderson-Fabry disease. Rapid Commun. Mass Spectrom. 16, 1507-1514. doi: $10.1002 / \mathrm{rcm} .728$

Campbell, D. I., Ferreira, C. R., Eberlin, L. S., and Cooks, R. G. (2012). Improved spatial resolution in the imaging of biological tissue using desorption electrospray ionization. Anal. Bioanal. Chem. 404, 389-398. doi: 10.1007/s00216-012-6173-6

Caprioli, R. M., Farmer, T. B., and Gile, J. (1997). Molecular imaging of biological samples: localization of peptides and proteins using MALDI-TOF MS. Anal. Chem. 69, 4751-4760. doi: 10.1021/ac970888i

Careri, M., Elviri, L., and Mangia, A. (1999). Liquid chromatography-electrospray mass spectrometry of beta-carotene and xanthophylls - validation of the analytical method. J. Chromatogr. A 854, 233-244. doi: 10.1016/S00219673(99)00541-5

Chen, Z. Y., Bogaerts, A., and Vertes, A. (2006). Phase explosion in atmospheric pressure infrared laser ablation from water-rich targets. Appl. Phys. Lett. 89, 3. doi: 10.1063/1.2243961

Colliver, T. L., Brummel, C. L., Pacholski, M. L., Swanek, F. D., Ewing, A. G., and Winograd, N. (1997). Atomic and molecular imaging at the single-cell level with TOF-SIMS. Anal. Chem. 69, 2225-2231. doi: 10.1021/ac9701748

Compton, L. R., Reschke, B., Friend, J., Powell, M., and Vertes, A. (2015). Remote laser ablation electrospray ionization mass spectrometry for non-proximate analysis of biological tissues. Rapid Commun. Mass Spectrom. 29, 67-73. doi: $10.1002 / \mathrm{rcm} .7077$

Dole, M., Mack, L. L., and Hines, R. L. (1968). Molecular beams of macroions. J. Chem. Phys. 49, 2240. doi: 10.1063/1.1670391

Downing, H. D., and Williams, D. (1975). Optical-constants of water in infrared. J. Geophys. Res. 80, 1656-1661. doi: 10.1029/JC080i012p01656

El-Baba, T. J., Lutomski, C. A., Wang, B. X., Inutan, E. D., and Trimpin, S. (2014). Toward high spatial resolution sampling and characterization of biological tissue surfaces using mass spectrometry. Anal. Bioanal. Chem. 406, 4053-4061. doi: 10.1007/s00216-014-7778-8

Feigl, P., Schueler, B., and Hillenkamp, F. (1983). LAMMA-1000, a new instrument for bulk microprobe mass analysis by pulsed laser irradiation. Int. J. Mass Spectrom. Ion Process. 47, 15-18. doi: 10.1016/0020-7381(83)8 7125-3

Hale, G. M., and Querry, M. R. (1973). Optical-constants of water in 200-nm to 200-mum wavelength region. Appl. Opt. 12, 555-563. doi: 10.1364/AO.12.000555

Hoelscher, D., Dhakshinamoorthy, S., Alexandrov, T., Becker, M., Bretschneider, T., Buerkert, A., et al. (2014). Phenalenone-type phytoalexins mediate resistance of banana plants (Musa spp.) to the burrowing nematode Radopholus similis. Proc. Natl. Acad. Sci. U.S.A. 111, 105-110. doi: $10.1073 /$ pnas. 1314168110

Hölscher, D., Shroff, R., Knop, K., Gottschaldt, M., Crecelius, A., Schneider, B., et al. (2009). Matrix-free UV-laser desorption/ionization (LDI) mass spectrometric imaging at the single-cell level: distribution of secondary metabolites of Arabidopsis thaliana and Hypericum species. Plant J. 60, 907-918. doi: 10.1111/j.1365-313X.2009.04012.x

Karas, M., Bachmann, D., Bahr, U., and Hillenkamp, F. (1987). Matrix-assisted ultraviolet-laser desorption of nonvolatile compounds. Int. J. Mass Spectrom. Ion Process. 78, 53-68. doi: 10.1016/0168-1176(87)87041-6

Karas, M., Bachmann, D., and Hillenkamp, F. (1985). Influence of the wavelength in high-irradiance ultraviolet-laser desorption mass-spectrometry of organicmolecules. Anal. Chem. 57, 2935-2939. doi: 10.1021/ac00291a042

Karas, M., and Kruger, R. (2003). Ion formation in MALDI: the cluster ionization mechanism. Chem. Rev. 103, 427-439. doi: 10.1021/cr010376a
Kebarle, P., and Verkerk, U. H. (2009). Electrospray: from ions in solution to ions in the gas phase, what we know now. Mass Spectrom. Rev. 28, 898-917. doi: $10.1002 /$ mas. 20247

Kertesz, V., and Van Berkel, G. J. (2010). Fully automated liquid extraction-based surface sampling and ionization using a chip-based robotic nanoelectrospray platform. J. Mass Spectrom. 45, 252-260. doi: 10.1002/jms.1709

Kroiss, J., Kaltenpoth, M., Schneider, B., Schwinger, M. G., Hertweck, C., Maddula, R. K., et al. (2010). Symbiotic streptomycetes provide antibiotic combination prophylaxis for wasp offspring. Nat. Chem. Biol. 6, 261-263. doi: 10.1038/nchembio.331

Laiko, V. V., Baldwin, M. A., and Burlingame, A. L. (2000). Atmospheric pressure matrix assisted laser desorption/ionization mass spectrometry. Anal. Chem. 72, 652-657. doi: 10.1021/ac990998k

Lanekoff, I., Heath, B. S., Liyu, A., Thomas, M., Carson, J. P., and Laskin, J. (2012). Automated platform for high-resolution tissue imaging using nanospray desorption electrospray ionization mass spectrometry. Anal. Chem. 84, 83518356. doi: 10.1021/ac301909a

Li, H., Smith, B. K., Mark, L., Nemes, P., Nazarian, J., and Vertes, A. (2015a). Ambient molecular imaging by laser ablation electrospray ionization mass spectrometry with ion mobility separation. Int. J. Mass Spectrom. 377, 681-689. doi: 10.1016/j.ijms.2014.06.025

Li, H., Smith, B. K., Shrestha, B., Mark, L., and Vertes, A. (2015b). “Automated cell-by-cell tissue imaging and single-cell analysis for targeted morphologies by laser ablation electrospray ionization mass spectrometry," in Mass Spectrometry Imaging of Small Molecules, ed. L. He (New York, NY: Humana Press), 117-127.

Li, Y., Shrestha, B., and Vertes, A. (2007). Atmospheric pressure molecular imaging by infrared MALDI mass spectrometry. Anal. Chem. 79, 523-532. doi: $10.1021 / \mathrm{ac} 061577 \mathrm{n}$

McMahon, J. M., Dookeran, N. N., and Todd, P. J. (1995). Organic ion imaging beyond the limit of static secondary-ion mass-spectrometry. J. Am. Soc. Mass Spectrom. 6, 1047-1058. doi: 10.1016/1044-0305(95)00526-9

Mohr, W., Vagner, T., Kuypers, M. M., Ackermann, M., and Laroche, J. (2013). Resolution of conflicting signals at the single-cell level in the regulation of cyanobacterial photosynthesis and nitrogen fixation. PLOS ONE 8:e66060. doi: 10.1371/journal.pone.0066060

Nemes, P., Barton, A. A., Li, Y., and Vertes, A. (2008). Ambient molecular imaging and depth profiling of live tissue by infrared laser ablation electrospray ionization mass spectrometry. Anal. Chem. 80, 4575-4582. doi: $10.1021 /$ ac8004082

Nemes, P., Barton, A. A., and Vertes, A. (2009). Three-dimensional imaging of metabolites in tissues under ambient conditions by laser ablation electrospray ionization mass spectrometry. Anal. Chem. 81, 6668-6675. doi: $10.1021 /$ ac900745e

Nemes, P., Huang, H. H., and Vertes, A. (2012). Internal energy deposition and ion fragmentation in atmospheric-pressure mid-infrared laser ablation electrospray ionization. Phys. Chem. Chem. Phys. 14, 2501-2507. doi: 10.1039/c2cp2 3411d

Nemes, P., and Vertes, A. (2007). Laser ablation electrospray ionization for atmospheric pressure, in vivo, and imaging mass spectrometry. Anal. Chem. 79, 8098-8106. doi: 10.1021/ac071181r

Nemes, P., Woods, A. S., and Vertes, A. (2010). Simultaneous imaging of small metabolites and lipids in rat brain tissues at atmospheric pressure by laser ablation electrospray ionization mass spectrometry. Anal. Chem. 82, 982-988. doi: 10.1021/ac902245p

Nielen, M. W. F., and van Beek, T. A. (2014). Macroscopic and microscopic spatially-resolved analysis of food contaminants and constituents using laserablation electrospray ionization mass spectrometry imaging. Anal. Bioanal. Chem. 406, 6805-6815. doi: 10.1007/s00216-014-7948-8

Parsiegla, G., Shrestha, B., Carriere, F., and Vertes, A. (2012). Direct analysis of phycobilisomal antenna proteins and metabolites in small cyanobacterial populations by laser ablation electrospray ionization mass spectrometry. Anal. Chem. 84, 34-38. doi: 10.1021/ac202831w

Robichaud, G., Barry, J. A., and Muddiman, D. C. (2014). IR-MALDESI mass spectrometry imaging of biological tissue sections using ice as a matrix. J. Am. Soc. Mass Spectrom. 25, 319-328. doi: 10.1007/s13361-013-0787-6

Saito, N., Timberlake, C. F., Tucknott, O. G., and Lewis, I. A. S. (1983). Fast atom bombardment mass-spectrometry of the anthocyanins Violanin and Platyconin. Phytochemistry 22, 1007-1009. doi: 10.1016/0031-9422(83)85043-2 
Sampson, J. S., Hawkridge, A. M., and Muddiman, D. C. (2006). Generation and detection of multiply-charged peptides and proteins by matrix-assisted laser desorption electrospray ionization (MALDESI) Fourier transform ion cyclotron resonance mass spectrometry. J. Am. Soc. Mass Spectrom. 17, 1712-1716. doi: 10.1016/j.jasms.2006.08.003

Shrestha, B., Javonillo, R., Burns, J. R., Pirger, Z., and Vertes, A. (2013). Comparative local analysis of metabolites, lipids and proteins in intact fish tissues by LAESI mass spectrometry. Analyst 138, 3444-3449. doi: 10.1039/c3an00631j

Shrestha, B., Nemes, P., Nazarian, J., Hathout, Y., Hoffman, E. P., and Vertes, A. (2010). Direct analysis of lipids and small metabolites in mouse brain tissue by AP IR-MALDI and reactive LAESI mass spectrometry. Analyst 135, 751-758. doi: $10.1039 / \mathrm{b} 922854 \mathrm{c}$

Shrestha, B., Patt, J. M., and Vertes, A. (2011). In situ cell-by-cell imaging and analysis of small cell populations by mass spectrometry. Anal. Chem. 83, 2947-2955. doi: 10.1021/ac102958x

Shrestha, B., Sripadi, P., Reschke, B. R., Henderson, H. D., Powell, M. J., Moody, S. A., et al. (2014). Subcellular metabolite and lipid analysis of Xenopus laevis eggs by LAESI mass spectrometry. PLoS ONE 9:e115173. doi: 10.1371/journal.pone.0115173

Shrestha, B., and Vertes, A. (2009). In situ metabolic profiling of single cells by laser ablation electrospray ionization mass spectrometry. Anal. Chem. 81, 8265-8271. doi: 10.1021/ac901525g

Shrivas, K., and Setou, M. (2012). "Imaging mass spectrometry: sample preparation, instrumentation, and applications," in Advances in Imaging and Electron Physics, Vol. 171, ed. P. W. Hawkes (Waltham: Academic Press), 145-193. doi: 10.1016/b978-0-12-394297-5.00004-0

Shroff, R., Schramm, K., Jeschke, V., Nemes, P., Vertes, A., Gershenzon, J., et al. (2015). Quantification of plant surface metabolites by matrixassisted laser desorption-ionization mass spectrometry imaging: glucosinolates on Arabidopsis thaliana leaves. Plant J. 81, 961-972. doi: 10.1111/tpj. 12760

Sripadi, P., Nazarian, J., Hathout, Y., Hoffman, E. P., and Vertes, A. (2009). In vitro analysis of metabolites from the untreated tissue of Torpedo californica electric organ by mid-infrared laser ablation electrospray ionization mass spectrometry. Metabolomics 5, 263-276. doi: 10.1007/s11306-008-0147-x

Stolee, J. A., Shrestha, B., Mengistu, G., and Vertes, A. (2012). Observation of subcellular metabolite gradients in single cells by laser ablation electrospray ionization mass spectrometry. Angew. Chem. Int. Edit. 51, 10386-10389. doi: 10.1002/anie.201205436
Stopka, S. A., Shrestha, B., Marechal, E., Falconet, D., and Vertes, A. (2014). Metabolic transformation of microalgae due to light acclimation and genetic modifications followed by laser ablation electrospray ionization mass spectrometry with ion mobility separation. Analyst 139, 5945-5953. doi: 10.1039/C4AN01368A

Svatos, A. (2010). Mass spectrometric imaging of small molecules. Trends Biotechnol. 28, 425-434. doi: 10.1016/j.tibtech.2010.05.005

Vaikkinen, A., Shrestha, B., Koivisto, J., Kostiainen, R., Vertes, A., and Kauppila, T. J. (2014). Laser ablation atmospheric pressure photoionization mass spectrometry imaging of phytochemicals from sage leaves. Rapid Commun. Mass Spectrom. 28, 2490-2496. doi: 10.1002/rcm.7043

Vaikkinen, A., Shrestha, B., Nazarian, J., Kostiainen, R., Vertes, A., and Kauppila, T. J. (2013). Simultaneous detection of nonpolar and polar compounds by heatassisted laser ablation electrospray ionization mass spectrometry. Anal. Chem. 85, 177-184. doi: 10.1021/ac302432h

Venter, A. R., Douglass, K. A., Shelley, J. T., Hasman, G., and Honarvar, E. (2014). Mechanisms of real-time, proximal sample processing during ambient ionization mass spectrometry. Anal. Chem. 86, 233-249. doi: $10.1021 /$ ac4038569

Vogel, A., and Venugopalan, V. (2003a). "Kinetics of phase transitions in pulsed IR laser ablation of biological tissues," in Proceedings of the Conference on Laser-Tissue Interaction XIV 4961, San Jose, 66-74. doi: 10.1117/12.519895

Vogel, A., and Venugopalan, V. (2003b). Mechanisms of pulsed laser ablation of biological tissues. Chem. Rev. 103, 577-644. doi: 10.1021/cr010379n

Whitehouse, C. M., Dreyer, R. N., Yamashita, M., and Fenn, J. B. (1985). Electrospray interface for liquid chromatographs and mass spectrometers. Anal. Chem. 57, 675-679. doi: 10.1021/ac00280a023

Yamashita, M., and Fenn, J. B. (1984). Electrospray ion-source - another variation on the free-jet theme. J. Phys. Chem. 88, 4451-4459. doi: 10.1021/j150664a002

Conflict of Interest Statement: The authors declare that the research was conducted in the absence of any commercial or financial relationships that could be construed as a potential conflict of interest.

Copyright (c) 2015 Bartels and Svatoš. This is an open-access article distributed under the terms of the Creative Commons Attribution License (CC BY). The use, distribution or reproduction in other forums is permitted, provided the original author(s) or licensor are credited and that the original publication in this journal is cited, in accordance with accepted academic practice. No use, distribution or reproduction is permitted which does not comply with these terms. 